\title{
PENGARUH TEPUNG MARMER TERHADAP SIFAT MEKANIK REACTIVE POWDER CONCRETE
}

\author{
Dewi Linggasari ${ }^{1}$, Arianti Sutandi², Widodo Kushartomo ${ }^{3}$ \\ ${ }^{1}$ Program Studi Sarjana Teknik Sipil, Universitas Tarumanagara Jakarta \\ Surel:dewil@ft.untar.ac.id \\ ${ }^{2}$ Program Studi Sarjana Teknik Sipil, Universitas Tarumanagara Jakarta \\ Surel: ariantis@ft.untar.ac.id \\ ${ }^{3}$ Program Studi Sarjana Teknik Sipil, Universitas Tarumanagara Jakarta \\ Surel:widodok@ft.untar.ac.id
}

\begin{abstract}
This research relates to the mechanical properties of reactive powder concrete due to the use of marble flour as one of its ingredients. The mechanical properties of concrete are influenced by many factors. One of the factors that influence its mechanical properties is the type and composition of concrete-forming materials. The physical and chemical properties of the material in the form of grain size and chemical composition each have a considerable impact on the mechanical properties of concrete. The use of marble flour in this study is also based on grain size and chemical composition of marble flour. The amount of marble flour used as an ingredient of reactive powder concrete is around 0\% - 30\% of the weight of cement. The treatment of the specimen was carried out by the evaporation immersion method at a temperature of $90^{\circ} \mathrm{C}-95^{\circ} \mathrm{C}$ for 8 hours. Mechanical testing was carried out at the age of 7 days on cylindrical and beam specimens, in the form of compressive strength, tensile strength and flexural strength. Keywords: mechanics, flour, marble, size, composition
\end{abstract}

\begin{abstract}
ABSTRAK
Penelitian ini berkaitan dengan sifat mekanik reactive powder concrete akibat penggunaan tepung marmer sebagai salah satu komponen material pembentuknya. Sifat mekanik beton dipengaruhi oleh banyak faktor. Salah satu faktor yang berpengaruh terhadap sifat mekanik tersebut adalah jenis dan komposisi bahan pembentuk beton. Sifat-sifat fisika dan kimia material berupa ukuran butiran dan komposisi kimia setiap memiliki dampak cukup besar pada sifat mekanik beton. Penggunaan tepung marmer dalam penelitian ini juga didasarkan pada ukuran butiran dan komposisi kimia yang dimiliki tepung marmer. Jumlah tepung marmer yang digunakan sebagai komponen pembentuk reactive powder concrete berkisar antara 0\% - 30\% terhadap berat semen. Perawatan benda uji dilakukan dengan metode perendaman penguapan pada temperatur $90^{\circ} \mathrm{C}-95^{\circ} \mathrm{C}$ selama 8 jam. Pengujian mekanik dilakukan pada umur 7 hari pada benda uji berbentuk silinder dan balok, berupa kuat tekan, kuat tarik belah dan kuat lentur.
\end{abstract}

Kata kunci: mekanik, tepung, marmer, ukuran, komposisi

\section{PENDAHULUAN}

Beton merupakan material yang sangat diperlukan dalam bidang industri konstruksi. Pada umumnya beton tersusun atas pasta semen dan agregat. Beton merupakan material heterogen dengan kekuatan tekan terbatas dan kekuatan tarik sangat rendah, sehingga dalam aplikasi struktur ditambahkan besi penulangan di dalam beton untuk meningkatkan kekuatan tarik. Perkembangan terkini dalam teknologi beton adalah reactive powder concrete (RPC). RPC menjadi sebuah 
pilihan yang dapat digunakan untuk menggantikan beton biasa dalam segala hal penggunaan di bidang konstruksi.

RPC merupakan material beton komposit yang memiliki kekuatan dan keuletan tinggi serta porositas rendah. RPC tersusun atas semen, air, silica fume, tepung kuarsa, pasir kuarsa dan serat baja. Selain komposisi material dan kualitas material penyusun. Faktor utama yang menunjang kekuatan RPC adalah volume pori (Richard dkk, 1995). Pada kebanyakan material getas, kekuatan dan porosistas dapat dikorelasikan sebagai sebuah persamaan

$$
\mathrm{S}=\mathrm{S}_{0} \mathrm{e}^{-\mathrm{kP}}
$$

dimana: $\mathrm{S}=$ kekuatan, $\mathrm{S}_{0}=$ kekuatan jika porositasnya $0, \mathrm{k}=$ konstanta dan $\mathrm{P}=$ jumlah pori.

Pada persamaan-1 tersebut menunjukkan jika jumlah porositas semakin besar maka kekuatannya juga akan semakin rendah. Dengan mengeliminasi agregat kasar sehingga seluruh komponen penyusunnya berupa tepung, RPC dapat tersusun secara kompak dan homogen, jauh lebih baik bila dibandingkan dengan beton biasa maupun dengan beton berkinerja tinggi (High Performance Concrete).

Namun demikian ukuran butiran maksimum berpengaruh pada volume pori, lekatan serat dan kinerja campuran selama proses pembuatan RPC. Volume pori yang semakin banyak berakibat fungsi serat menjadi kurang optimum, beban yang dipikul pada material komposit seperti RPC didistribusikan secara merata pada komponen-komponennya yaitu serat dan matrik, sehingga pada setiap komponen tersebut mengalami tegangan dan regangan yang berdampak pada fracture strength dan kuat tekan material komposit tersebut.

Penelitan yang telah dilakukan terhadap RPC (Kushartomo dkk, 2015) masih menunjukkan adanya kelemahan. Salah satu diantaranya adalah penggunaan tepung kuarsa. Tepung kuarsa dalam pembuatan RPC mempunyai fungsi sebagai pengisi pori. Dalam ukuran yang sangat kecil, tekanan tinggi dan temperatur yang tinggi selama pemeliharaan RPC, tepung kuarsa mampu bereaksi dengan C-S-H membentuk xonolite, sehingga kekuatan tekan RPC mampu meningkat secara signifikan (Kushartomo dkk, 2013). Di Indonesia tepung kuarsa bukan merupakan barang yang mudah untuk didapatkan. Guna mendapatkannya diperlukan import dari negara China, India atau Eropa sehingga keberlanjutan dalam pembuatan RPC menjadi kendala yang sangat besar.

Penelitian ini akan menggunakan tepung marmer sebagai ganti tepung silika dalam pembuatan RPC. Alasan penggunaan tepung marmer sebagai ganti tepung silika dalam pembuatan RPC adalah pertama tepung marmer mengandung kalsium sebagai komponen utamanya. Kalsium ini diharapkan dapat bereaksi dengan mikro silika dalam reaksi pozzolanic membentuk senyawa kalsium silikat hidrat. Semakin banyak volume kalsium silikat hidrat terbentuk maka kekuatan RPC akan bertambah besar seperti yang sudah dijelaskan tersebut diatas (Chavhan dkk, 2014 dan Corinaldesi dkk, 2010). Kedua Tepung marmer merupakan bahan yang mudah didapatkan di Indonesia dan tepung marmer merupakan limbah pabrik produksi batu marmer. Dengan demikian 
pemanfaatan limbah tepung marmer sebagai bahan pembuat RPC dapat mengurangi pencemeran lingkungan.

Dengan memperhatikan uraian tersebut diatas sehingga perlu dilakukan penelitian terhadap penggunaan tepung marmer untuk mengamati perilaku fracture strength dan kuat tekan reactive powder concrete terhadap ukuran butiran maksimum dan pengaruh komposisi kimia.

\section{METODE PENELITIAN}

Untuk dapat mencapai tujuan, dan menjawab semua pertanyaan pada penelitian yang akan dikerjakan ini, metode penelitian yang digunakan dalam pengumpulan data adalah penelitian eksperimental dimana sejumlah pengujian, perawatan dan metode karakterisasi dikerjakan untuk menentukan pengaruh ukuran butiran maksimal terhadap nilai fracture strength dan kuat tekan RPC dengan langkah-langkah penelitian seperti berikut.

Material yang diperlukan untuk pembuatan benda uji berupa semen, silica fume, pasir dengan ukuran butiran $150 \mu \mathrm{m}-2400 \mu \mathrm{m}$, tepung marmer dengan ukuran butiran $30 \mu \mathrm{m}-50 \mu \mathrm{m}$. Benda uji dibuat dalam bentuk silinder silinder berukuran $\varnothing 75,0 \mathrm{~mm}$ tinggi $150,0 \mathrm{~mm}$, dan prisma berukuran 100,0 mm x 100,0 $\mathrm{mm}$ x 400,0 $\mathrm{mm}$. Seluruh benda uji dipelihara dengan menggunakan peralatan Steam Generator pada temperature $90{ }^{\circ} \mathrm{C}-95^{\circ} \mathrm{C}$ selama 8 jam. Pengujian kuat tekan, kuat tarik belah dan kuat lentur dilakukan setelah benda uji berumur 7 hari. Pengamatan struktur mikro yang akan dilakukan adalah SEM. Pengamatan dengan scaning electron miroscopy (SEM) dilakukan untuk memeriksa gambar morfologi butiran dan $\mathrm{CSH}$ dan $\mathrm{CH}$. Rencana campuran benda uji di buat dengan persamaan seperti berikut:

$$
V_{a}+V_{s}+V_{s f}+V_{m}+V_{p}+V_{s p}=1
$$

Keterangan:

$\mathrm{V}=$ volume; $\mathrm{s}=$ semen; $\mathrm{sf}=$ silica fume $; \mathrm{m}=$ marmer; $\mathrm{p}=$ pasir; $\mathrm{sp}=$ super plasticizer

Rencana lengkap campuran diuraikan dalam Tabel 1 berikut.

Tabel 1 Perancangan campuran contoh uji RPC

\begin{tabular}{lccccccc}
\hline \multicolumn{1}{c}{ Material } & C-0 & C-1 & C-2 & C-3 & C-4 & C-5 & C-6 \\
\hline Semen & 1,00 & 1,00 & 1,00 & 1,00 & 1,00 & 1,00 & 1,00 \\
\hline Air & 0,20 & 0,20 & 0,20 & 0,20 & 0,20 & 0,20 & 0,20 \\
\hline Silica fume & 0,25 & 0,25 & 0,25 & 0,25 & 0,25 & 0,25 & 0,25 \\
\hline $\begin{array}{l}\text { Tepung } \\
\text { marmer }\end{array}$ & 0,00 & 0,50 & 0,10 & 0,15 & 0,20 & 0,25 & 0,30 \\
\hline Pasir & 1,50 & 0,20 & 0,20 & 0,20 & 0,20 & 0,20 & 0,20 \\
\hline $\begin{array}{l}\text { Super } \\
\text { plasticizer }\end{array}$ & 0,03 & 0,25 & 0,25 & 0,25 & 0,25 & 0,25 & 0,25 \\
\hline
\end{tabular}




\section{HASIL DAN PEMBAHASAN}

\section{Data Pengujian}

Data yang di sudah diperoleh dalam penelitian ini berupa ukuran butiran tepung marmer dan pasir, properties pasir silica, pengujian kuat tekan, pengujian kuat tarik belah dan pengujian kuat lentur benda uji beton. Hasil-hasil pengujian tersebut disajikan sebagai berikut.

\section{Ukuran butiran tepung marmer dan pasir silica}

Pengujian ukuran butiran tepung marmer dan pasir silica dilakukan di laboratorium Mekanika Tanah Universitas Tarumanagara hasil pengujian tersebut seperti disajikan pada Gambar 1

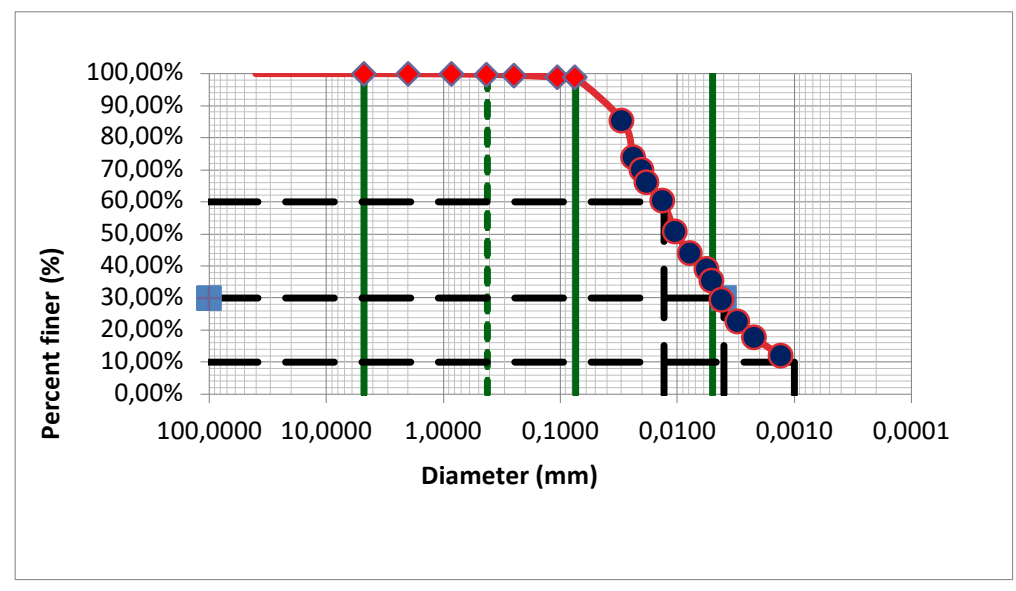

a

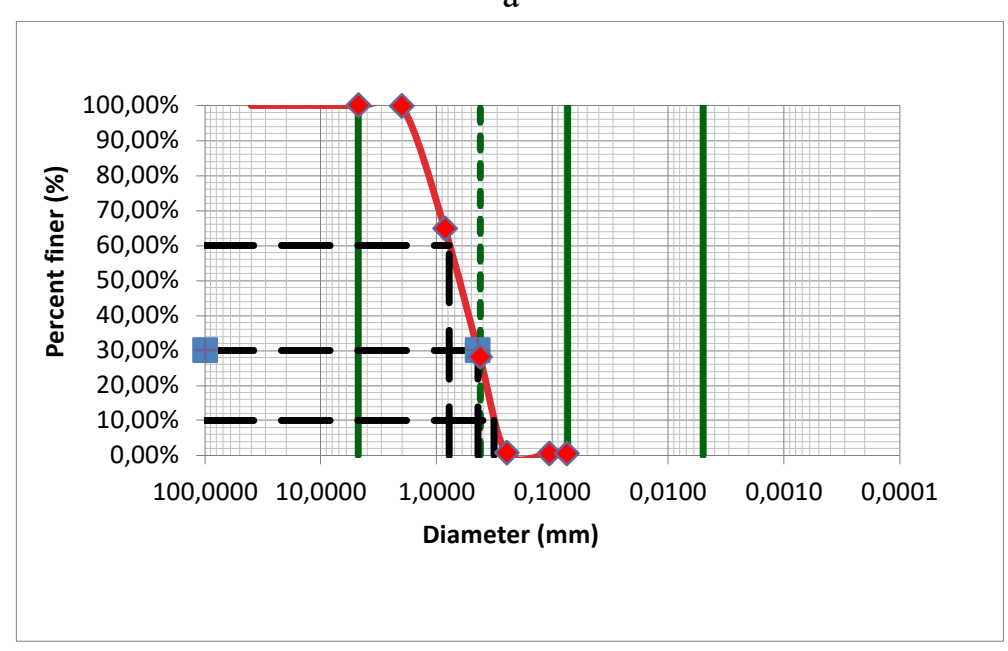

b

Gambar 1 (a) Distribusi butiran tepung marmer, (b) Distribusi butiran pasir silika

\section{Pengujian kuat tekan}

Pengujian kuat tekan, belah dan lentur dilakukan di laboratorium Konstruksi dan Teknologi Beton Universitas Tarumanagara, terhadap 7 variasi campuran. Hasil pengujian tersebut disajikan pada Table 2 berikut

Tabel 2. Kuat tekan benda uji silinder beton

\begin{tabular}{cccc}
\hline \multirow{2}{*}{ No Kode } & Tekan & Tarik & Lentur \\
\cline { 3 - 4 } & & $\mathbf{N} / \mathbf{m m}^{2}$ & \\
\hline
\end{tabular}




\section{Pembahasan}

\begin{tabular}{lllll}
1 & C-0 & 42,80 & 4,64 & 6,23 \\
\hline 2 & C-1 & 49,72 & 3,73 & 4,98 \\
\hline 3 & C-2 & 59,15 & 3,39 & 4,52 \\
\hline 4 & C-3 & 62,65 & 3,28 & 4,33 \\
\hline 5 & C-4 & 65,68 & 3,20 & 4,25 \\
\hline 6 & C-5 & 61,66 & 3,83 & 5,31 \\
\hline 7 & C-6 & 44,97 & 4,88 & 6,05 \\
\hline
\end{tabular}

Pengujian yang dilakukan untuk mengetahui peranan tepung marmer pada pembentukan sifat mekanis reactive powder concrete (RPC) diperlukan untuk memenuhi spesifikasi teknis penggunaan tepung marmer pada RPC. Hasil pengujian sifat mekanis diatas secara jelas ditunjukkan pada grafik-grafik berikut ini.

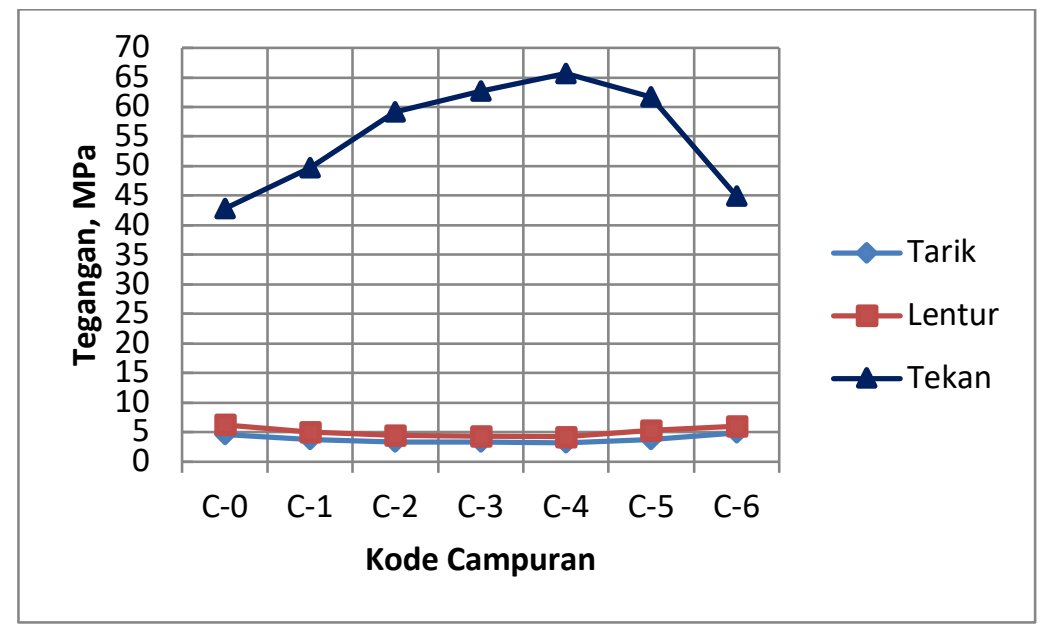

Gambar 2. Grafik perubahan kuat tekan, tarik, lentur RPC terhadap penambahan tepung marmer.

Gambar 2 menjelaskan peningkatan kuat tekan beton RPC terhadap penambahan tepung marmer (Kumar, 2015). Peningkatan kuat tekan maksimum terjadi pada penambahan tepung marmer sebanyak $20 \%$ terhadap berat semen. Penurunan kuat tekan beton RPC terjadi bila jumlah tepung marmer yang ditambahkan lebih dari 20\%. Peningkatan kuat tekan beton RPC terjadi akibat peran tepung marmer dalam memperbaiki struktur mikro beton RPC (Kalchuri, 2015). Alasan pertama yang mendasari peranan tepung marmer dalam meningkatkan kuat tekan beton RPC adalah 30\% ukuran butiran tepung marmer berkisar antara $100 \mathrm{~nm}$ sampai $1 \mathrm{~nm}$ seperti yang ditunjukkan pada Gambar 1. Ukuran butiran ini jauh lebih kecil dibandingkan dengan ukuran butiran semen yang hanya berkisar $75 \mu \mathrm{m}$. Ukuran butiran tepung marmer yang lebih kecil dari butiran semen, memudahkan tepung marmer menyisip atau mengisi pori beton RPC (Rai, 2011) seperti yang ditunjukkan pada Gambar 3. Gambar 4 merupakan sampel yang diambil dari Campuran-3, dengan penggunaan tepung marmer sebanyak $10 \%$. Pada gambar tersebut tepung marmer tidak berbentuk bulat sperikal namun berbentuk tidak beraturan berwarna putih. Tepung marmer menempati 
bagian-bagian yang kosong seperti yang ditunjukkan pada tanda panah sehingga beton RPC menjadi bertambah solid (Rao, 2016).

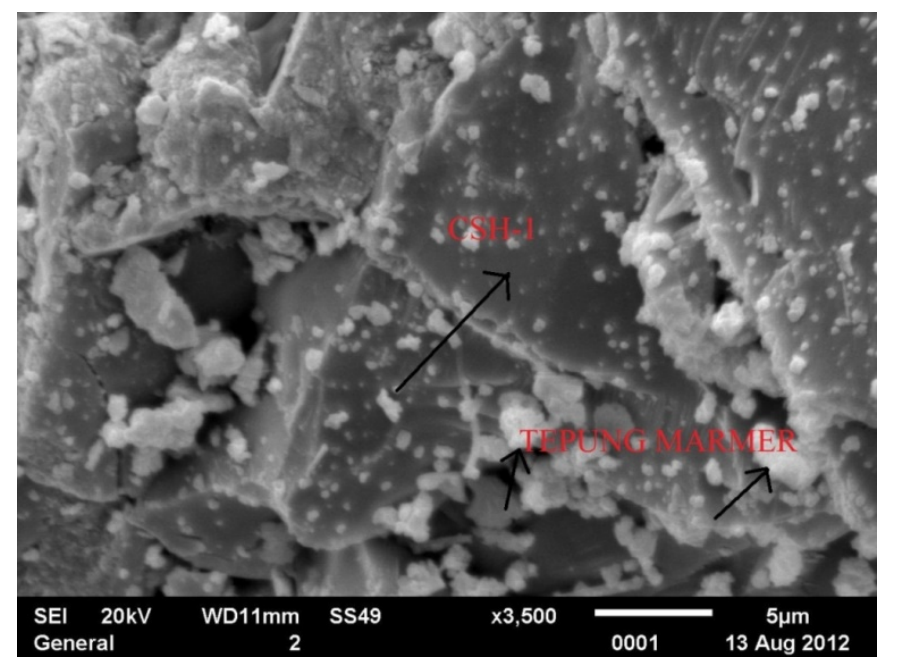

Gambar 3 Penyisipan tepung marmer pada beton RPC

Alasan ke dua tepung marmer bereaksi dengan silica fume membentuk C-S-H $\mathrm{H}_{\text {II }}$ yang dikenal dengan tobermorit. C-S-H II. Reaksi ini dikenal dengan sebutan reaksi pozolanik, reaksi pozolanik dapat terjadi mengingat silica fume memiliki struktur Kristal amorf yang sangat reaktif dan dapat bereaksi pada temperature ruang. Adapun rekasi yang terjadi antara tepung marmer dengan silica fume dituliskan sebagai berikut:

$$
\begin{array}{ccc}
\mathrm{CaO}+ & \begin{array}{c}
\mathrm{H}_{2} \mathrm{O} \\
\text { Tepung Marmer }
\end{array} \text { air } & \begin{array}{c}
\mathrm{Ca}(\mathrm{OH})_{2} \\
\text { Portlandite }
\end{array} \\
\mathrm{Ca}(\mathrm{OH})_{2}+\mathrm{SiO}_{2}+\mathrm{H}_{2} \mathrm{O} & \text { C-S-H } \mathrm{H}_{\mathrm{II}}
\end{array}
$$

Pembentukan C-S-H $\mathrm{H}_{\text {II }}$ dibuktikan dengan gambar strukturmikro penggunaan tepung marmer sebanyak 20\%, seperti yang ditunjukkan pada Gambar 4 berikut.

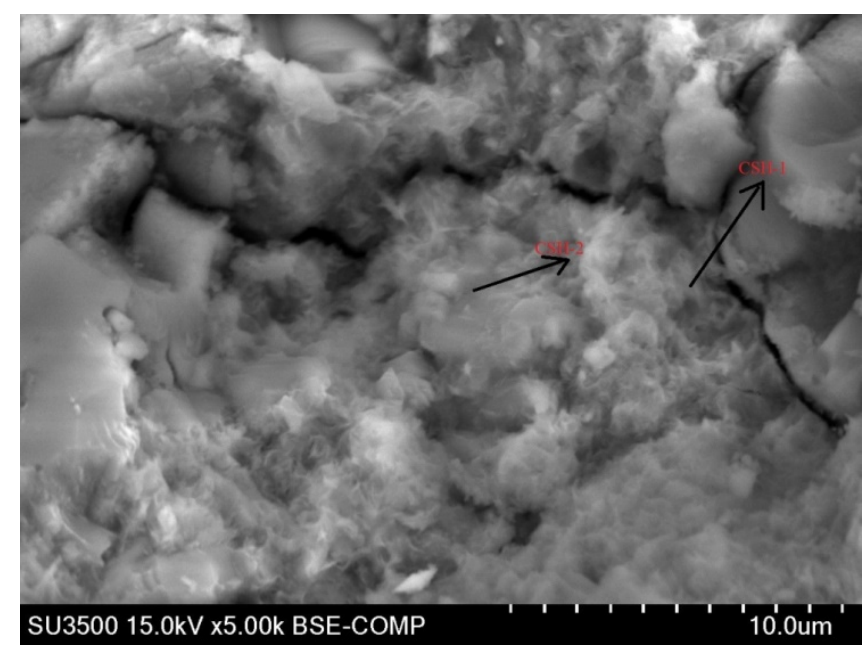


Gambar 4. Pembentukan C-S-HII pada penggunaan tepung marmer sebesar 20\%.

Penambahan tepung marmer lebih dari 20\% terhadap berat semen, mengakibatkan penurunan nilai kuat tekan beton RPC. Penurunan nilai kuat tekan ini diakibatkan adanya pengotor dalam jumlah cukup banyak yang berasal dari tepung marmer (Talah, 2015). Analisis ini dibuktikan dari gambar pemeriksaan struktur mikro seperti disajikan pada Gambar 5 berikut.

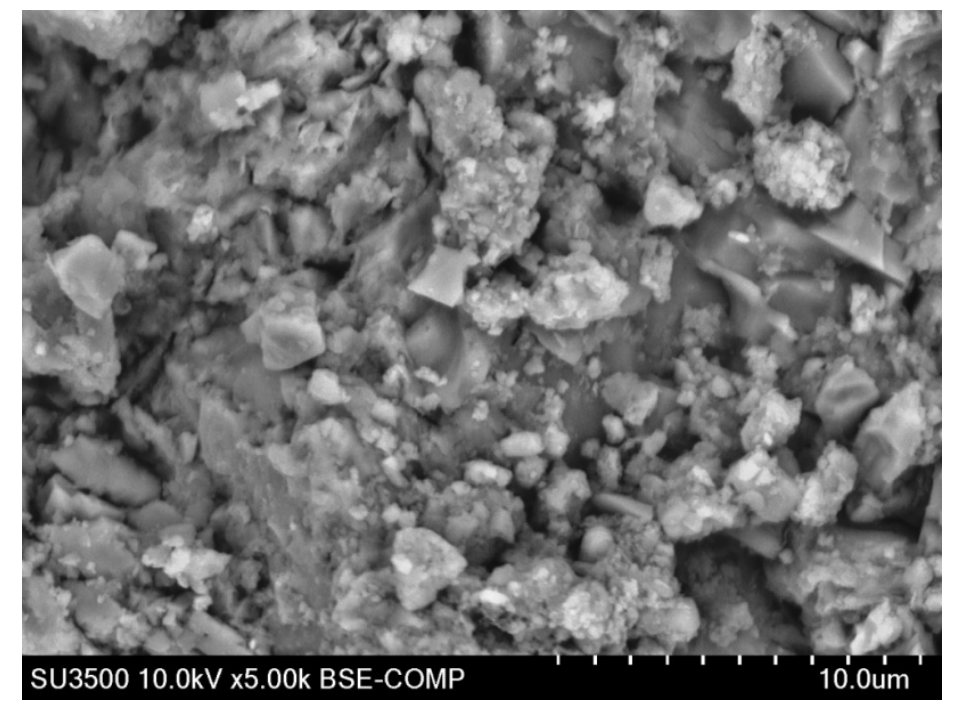

Gambar 5. Pengotor yang berasal dari tepung marmer

Gambar 2 juga memperlihatkan penurunan nilai kuat tarik belah dan kuat lentur terhadap penambahan tepung marmer. Penurunan ini sejalan dengan sifat material, bahwa semakin kuat sebuah material maka material tersebut akan semakin mudah patah. Ini ditunjukkan dengan penurunan nilai kuat tarik belah dan kuat lentur balok RPC (Soliman, 2013, Sakalkale, 2014).

\section{KESIMPULAN}

Berdasarkan analisisi yang dilakukan maka penelitian yang telah dilakukan memberikan kesimpulan sebagai berikut:

1. Tepung marmer dapat meningkatkan kuat tekan beton RPC dengan jalan memperbaiki strukur mikro berupa pembentukan C-S-H

2. Ukuran butiran tepung marmer yang lebih kecil dibandingkan dengan ukuran butiran semen, memudahkan tepung marmer masuk pori atau void RPC sehingga benton RPC menjadi bertambah kompak atau padat.

3. Penambahan tepung marmer yang belebihan, mengakibatkan penurunan nilai kuat tekan beton RPC. Batas penggunaan maksimum tepung sebagai additive dalam beton RPC sebanyak $20 \%$ terhadap berat semen.

4. Peningkatan kuat tekan beton mengakibatkan beton semakin bertambah getas. Ini ditunjukkan dengan penurunan nilai kuat tarik belah dan kuat lentur beton RPC. 


\section{REFERENSI}

Chavhan, Pooja J.; Bhole, S. D. (2014). "To Study the Behaviour of Marble Powder as Supplementry Cementitious Material in Concrete", International Journal of Engineering Research and Applications, Vol. 4, 377-381.

Corinaldesi, Valeria; Moriconi, Giacomo; Naik, Tarun R. (2010). "Characterization Of Marble Powder For Its Use In Mortar And Concrete", Construction and Building Materials, Vol. 24, 113-117.

Kalchuri, Bhupendra Singh; Chandak, Rajeev; Yadav, R.K. (2015) "Study On Concrete Using Marble Powder Waste As Partial Replacement Of Sand" International Journal Of Engineering Research And Applications, Vol. 5, 87-89.

Kumar, Ranjan; Kumar, Shyam Kishor (2015) "Partial Replacement Of Cement With Marble Dust Powder", International Journal Of Engineering Research And Applications, Vol. 5, 106114

Kushartomo, W.; Bali, Ika; Sulaiman, B. (2015). "Mechanical Behaviour of Reactive Powder Concrete with Glass Powder Subtitute", The 5th International Conference of Euro Asia Civil Engineering Forum (EACEF5), Procidia Engineering, Elsevier, 617-622.

Kushartomo, W.; Makarim, C.A.; Sumawiganda, S.; Supartono, .FX. (2013). "Pengaruh Penambahan Quartz Powder pada Reactive Powder Concrete terhadap Terbentuknya Kalsium-Silikat-Hidrat", Jurnal Teknik Sipil-ITB, Vol. 20 No.3, 187-194

Rai , Baboo; H. Khan Naushad; Kr, Abhishek; S, Tabin Rushad; K. Duggal S. (2011) "Influence of Marble Powder/Granules In Concrete Mix", International Journal Of Civil And Structural Engineering, Vol. 1 No. 4, 827-834

Rao, B. Khrisna, (2016). "A Study on Performance of Concrete Containing Marble Powder and Quarry Dust", International Journal of Inovation and Technology, Vol. 6, 67-72.

Richard, P.; Cheyrezy, M., (1995). "Composition of Reactive Powder Concretes". Cement Concrete Research, Vol. 25 No.7, pp. 1501-1511.

Sakalkale, Aalok D.; Dhawale, G. D.; Kedar, R. S. (2014). "Experimental Study On Use Of Waste Marble Dust In Concrete", International Journal Of Engineering Research And Applications, Vol. 4, October, 44-50.

Soliman, Noha M. (2013). "Effect of using Marble Powder in Concrete Mixes on the Behavior and Strength of R.C. Slabs", International Journal of Current Engineering and Technology, Vol.3, No.5, December, 1863-1870.

Talah, A.; Kharchi, F.; Chaid, R. (2015). "Influence Of Marble Powder On High Performance Concrete Behavior", 1st International Conference On Structural Integrity, Procedia Engineering 114, 685-690. 